\title{
Aerodynamic research of a racing car based on wind tunnel test and computational fluid dynamics
}

\author{
Jianfeng Wang ${ }^{1,2}$, Hao Li ${ }^{1}$, Yiqun $\mathrm{Liu}^{1,2}$, Tao Liu ${ }^{1}$, and Haibo $\mathrm{Gao}^{2}$ \\ ${ }^{1}$ School of Automotive Engineering, Harbin Institute of Technology, Weihai, 264209, China \\ 2 State Key Laboratory of Robotics and System, Harbin Institute of Technology, Harbin, 150080, China
}

\begin{abstract}
Wind tunnel test and computational fluid dynamics (CFD) simulation are two main methods for the study of automotive aerodynamics. CFD simulation software solves the results in calculation by using the basic theory of aerodynamic. Calculation will inevitably lead to bias, and the wind tunnel test can effectively simulate the real driving condition, which is the most effective aerodynamics research method. This paper researches the aerodynamic characteristics of the wing of a racing car. Aerodynamic model of a racing car is established. Wind tunnel test is carried out and compared with the simulation results of computational fluid dynamics. The deviation of the two methods is small, and the accuracy of computational fluid dynamics simulation is verified. By means of CFD software simulation, the coefficients of six aerodynamic forces are fitted and the aerodynamic equations are obtained. Finally, the aerodynamic forces and torques of the racing car travel in bend are calculated.
\end{abstract}

\section{Introduction}

Aerodynamics is one of the most important factors affecting dynamic performance of a racing car. Especially in some open-cab and open-wheel car, air flows through car body should be properly channelled to provide reasonable downward pressure. Wing through car body can be divided into three parts, top wing, both sides' wing and bottom wing. Upper wing moves along the surface of the car, reaching the tail-wing area at the end of the car. The wing on both sides of the car is also divided into two parts, the flow front of the wheel and the flow to the radiator box through the wheel and the body. Using the diversion of the front wing to guide the wing inward or outward in front of the wheel, make the wing bypass the tire to reduce the air drag force caused by the tire. The bottom of the air is the need for reasonable guidance to allow the air to flow smoothly through the car chassis.

For research of aerodynamics characteristics of racing car, mainly use wind tunnel experiment and simulated by computational fluid dynamics (CFD) software. CFD is a system analysis method and tool for simulating fluid flow, heat transfer and related transfer phenomena by computer. The basic idea of CFD is the original in time domain and space domain continuous physical quantity field, replaced by a series of discrete points on the value of the variable, and through the principles and methods to establish certain algebraic equations reflect the discrete points on the relationship between variables, and then solving algebraic equations to obtain the approximation of the field variables solution. The relationship between discrete points conforms to fluid mass conservation, momentum conservation and energy conservation, which are the fluid control equations. In order to verify the accuracy of the calculation of fluid analysis software, using the wind tunnel experiment on wing was tested. MohrfeldHalterman described a high fidelity vehicle aerodynamic model and presented a comparison between the effects of this proposed model and a conventional quasi steadystate aerodynamic model on race vehicle simulation results [1]. J. D. Kee, et al [2] researched driving stability of a passenger car at high-speed and under crosswind conditions by wind tunnel test. Roberts, et al. [3] established the fundamental aerodynamic flow features of a racing car's front wing operating at yaw. A. Buljac, et al. [4] developed a computational model to analyse aerodynamic loads and flow characteristics of the rear wing. M. D. Soso and P. A. Wilson [5] researched aerodynamic factors which influence the creation of overtaking opportunities in the racing car by wind tunnel test. A. Altinisik, et al. [6] studied the drag forces and the pressure distributions of the model FIAT Linea at increasing yaw angle and two-vehicle platoon. Experiments were performed in the wind tunnel for the yaw angles of $0 \mathrm{deg}, 5 \mathrm{deg}$, and $10 \mathrm{deg}$ due to the test section dimensional restriction. He obtained the drag coefficients for three different test configurations, and the comparison of the drag coefficients for all three coastdown configurations were in good agreement with the CFD results and FIAT wind tunnel results [7]. Zhang Yingchao, et al. [8] researched on the aerodynamic drag both in wind tunnel test and CFD, and obtained the reasons for the drag coefficients increased. 


\section{Six aerodynamic forces}

The influence of aerodynamics on racing car is realized mainly through aerodynamic and aerodynamic moment. The driving speed, body shape and sideslip angle of the car are important factors to influence the aerodynamic force and aerodynamic moment. Aerodynamic forces and moments are composed by three vertical forces and torques around $X$ axis and $Y$ axis and $Z$ axis, also known as six aerodynamic component forces, mainly includes drag force $F_{\mathrm{D}}$, lift force $F_{\mathrm{L}}$, side force $F_{\mathrm{S}}$, rolling moment $T_{\mathrm{RM}}$, pitching moment $T_{\mathrm{PM}}$ and yawing moment $T_{\mathrm{YM}}$, as shown in Figure 1.

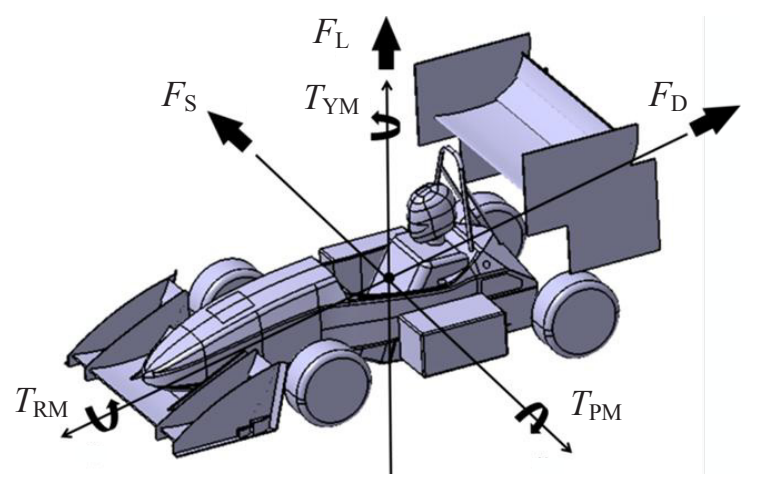

Figure 1. Diagram of six aerodynamic component forces.

According to the ISO standard, the origin of aerodynamic coordinate is located in the center of front and rear axles. Six aerodynamic component forces can be defined in Equation (1).

$$
\left\{\begin{array}{l}
F_{D}=\frac{1}{2} C_{D} A \rho u^{2} \quad F_{L}=\frac{1}{2} C_{L} A \rho u^{2} \quad F_{S}=\frac{1}{2} C_{S} A \rho u^{2} \\
T_{R M}=\frac{1}{2} C_{R M} A \rho L u^{2} \quad T_{P M}=\frac{1}{2} C_{P M} A \rho L u^{2} \\
T_{Y M}=\frac{1}{2} C_{Y M} A \rho L u^{2}
\end{array}\right.
$$

where $F_{\mathrm{D}}(\mathrm{N})$ is drag force, $F_{\mathrm{L}}(\mathrm{N})$ is lift force, $F_{\mathrm{S}}(\mathrm{N})$ is side force, $C_{\mathrm{L}}$ is lift force coefficient, $C_{\mathrm{D}}$ is drag force coefficient, $C_{\mathrm{S}}$ is side force coefficient, $T_{\mathrm{RM}}(\mathrm{Nm})$ is rolling moment, $T_{\mathrm{PM}}(\mathrm{Nm})$ is pitching moment, $T_{\mathrm{YM}}(\mathrm{Nm})$ is yawing moment, $C_{\mathrm{RM}}$ is rolling moment coefficient, $C_{\mathrm{PM}}$ is pitching moment coefficient, $C_{\mathrm{YM}}$ is yawing moment coefficient, $A$ is car's projection area (taken $1.15041 \mathrm{~m}^{2}$ ), $\rho$ is air density (taken $\left.1.18415 \mathrm{~kg} / \mathrm{m}^{3}\right), L$ is wheelbase (taken $1.53 \mathrm{~m}), u(\mathrm{~km} / \mathrm{h})$ is velocity.

\section{Wind tunnel test}

\subsection{Experimental installation}

The wind tunnel test is the most direct method to research aerodynamics of automobile and automobile parts. In order to study aerodynamic characteristics of the wing and the correctness of the comparison of CFD software, the wing experiment using wind tunnel. The wind tunnel in School of Automotive Engineering of Harbin Institute of Technology at Weihai is used in experiment, as shown in Figure 2. The wind tunnel is open type wind tunnel, wind tunnel test section size: $2.5 \mathrm{~m} \times 1.2 \mathrm{~m} \times 1 \mathrm{~m}$, wind speed can be adjusted continuously at the range of 2-30 $\mathrm{m} / \mathrm{s}$. The test system uses Donghua DH5902 test data acquisition system.

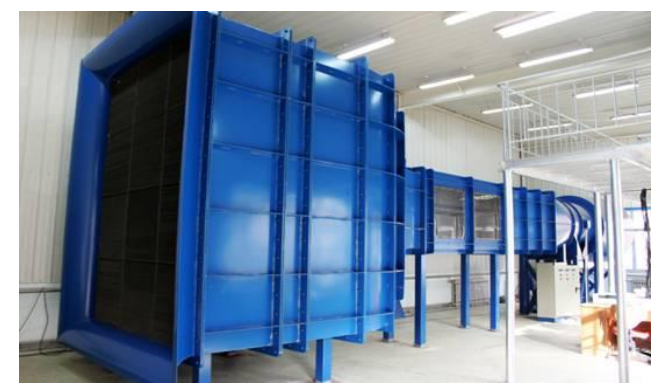

Figure 2. Photograph of wind tunnel.

In order to test the aerodynamic characteristics of wing, three aerodynamic component forces bar-shaped strain gauge balance was designed. A. L. Smith, et al. [9] designed a six component force balance using a combination of modelling and analysis techniques. The balance was designed for the measurement of impulsive aerodynamic forces and moments characteristic. The wing sample is well connected on the upper support by mechanical connection. The tray can be installed at the bottom of the tunnel. The rotation of the tray can realize the adjustment of wing's yaw angle. The lower support connects tray and strain gauge balance, and ensures the tested wing lift height can get rid of the influence of surface boundary layer.

The middle three-component bar-shaped strain gauge balance is the main body of the balance assembly. The balance is composed of three pieces of beam element and the vertical beam, the middle beam of three beams is used to measure normal force, under the symmetric set of two beams are used to measure the pitching moment. Four vertical beams are used to measure axial force element were used to measure the axial force. The strain sensors are arranged in the corresponding position to measure the wing's force and torque.

\subsection{Comparison between wind tunnel test and simulation results}

The pressure and drag force of the wing numbered NACA7048 is tested in wind tunnel experiment. At the same time, in accordance with the wind tunnel test conditions using computational fluid analysis STAR$\mathrm{CCM}$ to establish flow field simulation model shown in Figure 3.

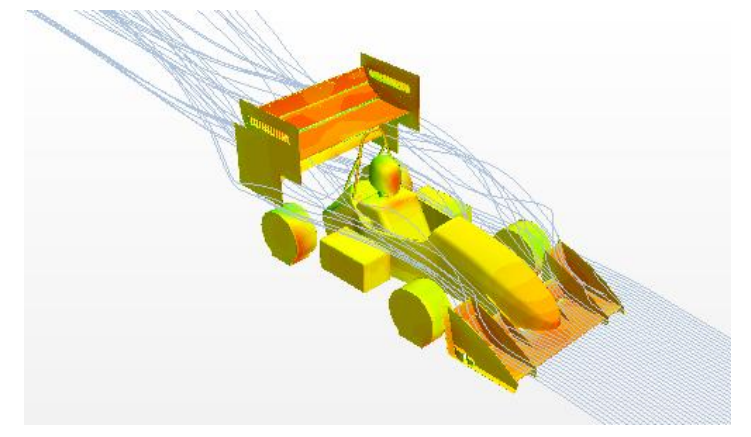

Figure 3. Simulation model in STAR-CCM. 
Wind tunnel experiment results and simulation results are compared as shown in Figure 4. The average relative error in less than $4 \%$. Therefore, simulation results are reliable and can be used for detailed analysis of the car in different conditions. Therefore, the following analysis of aerodynamic characteristics of fluid simulation can use STAR-CCM software.

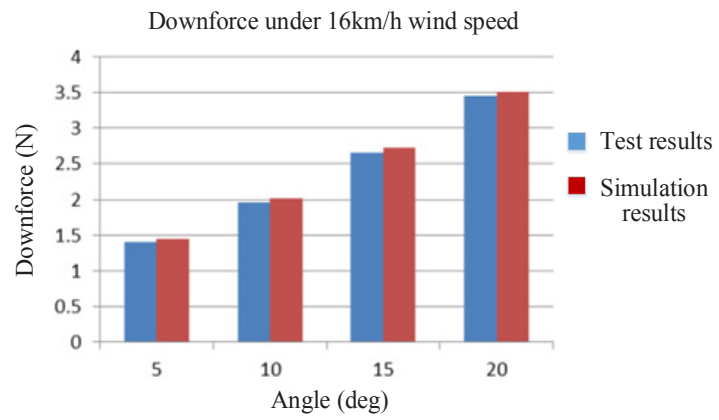

(a)

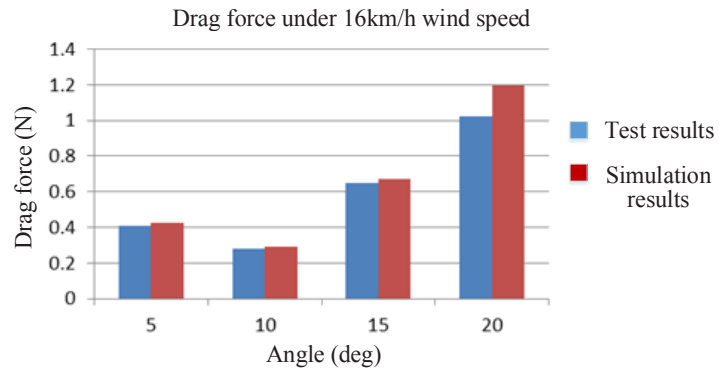

(b)

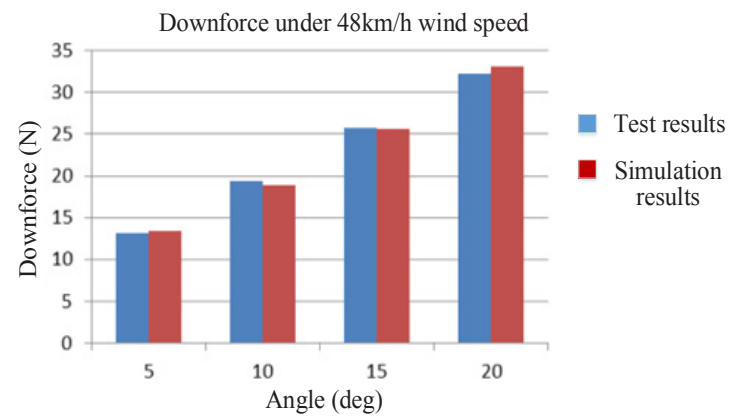

(c)

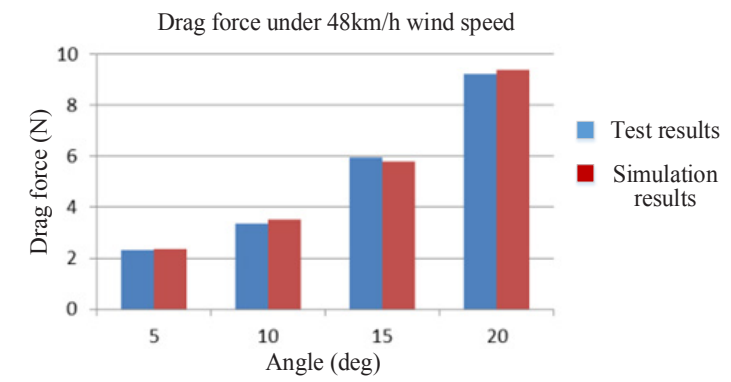

(d)

Figure 4. Comparison of wind tunnel test with simulation.

\section{Aerodynamic parameter fitting and performance analysis}

\subsection{Aerodynamic coefficients calculation}

The moving car's speed and direction is often inconsistent. In the analysis, discussing the crosswind for the car, the car in the steering process can be simplified to the wind blowing the car. The angle between the wind and the car is vehicle sideslip angle $\beta$. The body is fixed when solving the problem changing the direction of wind, and meanwhile simulates the cornering conditions. The vehicle coordinate system is same with flow field coordinate. $X$ axis of flow field and $X$ axis of vehicle has angle $\beta$ as the same. Entrance velocity $V$ of flow field is decomposed into windward speed $V_{\text {a }}$ along the $X$ axis and crosswind velocity $V_{\mathrm{w}}$ along the $Y$ axis as shown in Figure 5.

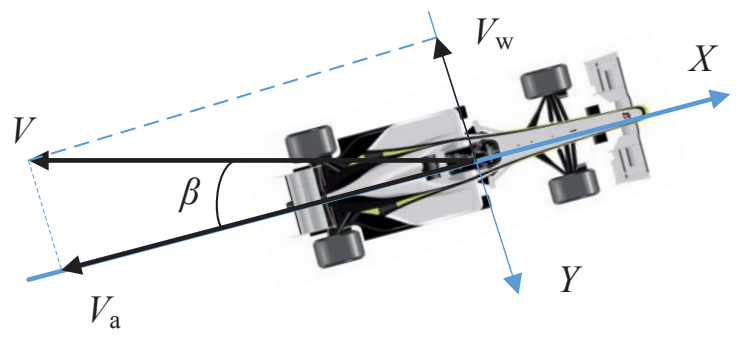

Figure 5. Diagram of racing car moving in bend.

This paper use CFD software STAR-CCM to compute the influence of aerodynamic coefficients by car's speed and sideslip angle quantitatively. Set gradient as $5 \mathrm{~km} / \mathrm{h}$, speed increased from $25 \mathrm{~km} / \mathrm{h}$ to $60 \mathrm{~km} / \mathrm{h}$. To set gradient as $2.5^{\circ}$, the sideslip angle increases from $0^{\circ}$ to $20^{\circ}$. The corresponding set of crosswind velocity $V_{\mathrm{w}}$ and windward velocity $V_{\mathrm{a}}$ are in Table 1 and Table 2.

Table 1. Crosswind velocity values of different sideslip angles.

\begin{tabular}{|c|c|c|c|c|c|}
\hline \multirow{2}{*}{\multicolumn{2}{|c|}{$\begin{array}{c}\text { Crosswind } \\
\text { velocity }(\mathrm{km} / \mathrm{h})\end{array}$}} & \multicolumn{4}{|c|}{ Sideslip angles $\left({ }^{\circ}\right)$} \\
\hline & & 2.5 & 5 & 7.5 & 10 \\
\hline \multirow{8}{*}{$\begin{array}{c}\text { Inlet } \\
\text { velocity } \\
(\mathrm{km} / \mathrm{h})\end{array}$} & 25 & 1.090 & 2.179 & 3.263 & 4.341 \\
\hline & 30 & 1.309 & 2.615 & 3.916 & 5.209 \\
\hline & 35 & 1.527 & 3.050 & 4.568 & 6.078 \\
\hline & 40 & 1.745 & 3.486 & 5.221 & 6.946 \\
\hline & 45 & 1.963 & 3.922 & 5.874 & 7.814 \\
\hline & 50 & 2.181 & 4.358 & 6.526 & 8.682 \\
\hline & 55 & 2.399 & 4.794 & 7.179 & 9.551 \\
\hline & 60 & 2.617 & 5.229 & 7.832 & 10.419 \\
\hline \multirow{2}{*}{\multicolumn{2}{|c|}{$\begin{array}{c}\text { Crosswind } \\
\text { velocity }(\mathrm{km} / \mathrm{h})\end{array}$}} & \multicolumn{4}{|c|}{ Sideslip angles $\left({ }^{\circ}\right)$} \\
\hline & & 12.5 & 15 & 17.5 & 20 \\
\hline \multirow{8}{*}{$\begin{array}{c}\text { Inlet } \\
\text { velocity } \\
(\mathrm{km} / \mathrm{h})\end{array}$} & 25 & 5.411 & 6.470 & 7.518 & 8.551 \\
\hline & 30 & 6.493 & 7.765 & 9.021 & 10.261 \\
\hline & 35 & 7.575 & 9.059 & 10.525 & 11.971 \\
\hline & 40 & 8.658 & 10.353 & 12.028 & 13.681 \\
\hline & 45 & 9.740 & 11.647 & 13.532 & 15.391 \\
\hline & 50 & 10.822 & 12.941 & 15.035 & 17.101 \\
\hline & 55 & 11.904 & 14.235 & 16.539 & 18.811 \\
\hline & 60 & 12.986 & 15.529 & 18.042 & 20.521 \\
\hline
\end{tabular}


Table 2. Windward velocity values of different sideslip angles.

\begin{tabular}{|c|c|c|c|c|c|}
\hline \multirow{2}{*}{\multicolumn{2}{|c|}{$\begin{array}{c}\text { Windward } \\
\text { velocity }(\mathrm{km} / \mathrm{h})\end{array}$}} & \multicolumn{4}{|c|}{ Sideslip angles $\left({ }^{\circ}\right)$} \\
\hline & & \multirow{2}{*}{$\begin{array}{c}2.5 \\
24.976\end{array}$} & \multirow{2}{*}{$\frac{5}{24.905}$} & \multirow{2}{*}{$\begin{array}{c}7.5 \\
24.786\end{array}$} & \multirow{2}{*}{$\begin{array}{c}10 \\
24.620\end{array}$} \\
\hline \multirow{8}{*}{$\begin{array}{c}\text { Inlet } \\
\text { velocity } \\
(\mathrm{km} / \mathrm{h})\end{array}$} & 25 & & & & \\
\hline & 30 & 29.971 & 29.886 & 29.743 & 29.544 \\
\hline & 35 & 34.967 & 34.867 & 34.701 & 34.468 \\
\hline & 40 & 39.962 & 39.848 & 39.658 & 39.392 \\
\hline & 45 & 44.957 & 44.829 & 44.615 & 44.316 \\
\hline & 50 & 49.952 & 49.810 & 49.572 & 49.240 \\
\hline & 55 & 54.948 & 54.791 & 54.529 & 54.164 \\
\hline & 60 & 59.943 & 59.772 & 59.487 & 59.088 \\
\hline \multirow{2}{*}{\multicolumn{2}{|c|}{$\begin{array}{c}\text { Windward } \\
\text { velocity }(\mathbf{k m} / \mathbf{h})\end{array}$}} & \multicolumn{4}{|c|}{ Sideslip angles $\left({ }^{\circ}\right)$} \\
\hline & & 12.5 & 15 & 17.5 & 20 \\
\hline \multirow{8}{*}{$\begin{array}{c}\text { Inlet } \\
\text { velocity } \\
(\mathrm{km} / \mathrm{h})\end{array}$} & 25 & 24.407 & 24.148 & 23.843 & 23.492 \\
\hline & 30 & 29.289 & 28.978 & 28.612 & 28.191 \\
\hline & 35 & 34.170 & 33.807 & 33.380 & 32.889 \\
\hline & 40 & 39.052 & 38.637 & 38.149 & 37.588 \\
\hline & 45 & 43.933 & 43.467 & 42.917 & 42.286 \\
\hline & 50 & 48.815 & 48.296 & 47.686 & 46.985 \\
\hline & 55 & 53.696 & 53.126 & 52.454 & 51.683 \\
\hline & 60 & 58.578 & 57.956 & 57.223 & 56.382 \\
\hline
\end{tabular}

The relationship among aerodynamic force coefficient, speed and sideslip angle are shown in Figure 6. The relationship among aerodynamic moment coefficient, speed and sideslip angle are shown in Figure 7. When the sideslip angle is fixed, there is no correlation among aerodynamic force and moment coefficient and speed. When the speed is fixed, with the increase of sideslip angle, aerodynamic force and torque coefficients showed a certain change regulation. Therefore, aerodynamic coefficients were fitted in this paper. The relationship between aerodynamic coefficient and sideslip angle is represented by semi-empirical equations. Select the average speed for calculating aerodynamic coefficients. The aerodynamic coefficients as shown in Equation (2), six aerodynamic component forces fitting coefficients are shown in Table 3.

$$
\left\{\begin{array}{l}
C_{L}=C_{L 1} \cdot \beta^{3}+C_{L 2} \cdot \beta^{2}+C_{L 3} \cdot \beta+C_{L 4} \\
C_{D}=C_{D 1} \cdot \beta^{3}+C_{D 2} \cdot \beta^{2}+C_{D 3} \cdot \beta+C_{D 4} \\
C_{S}=C_{S 1} \cdot \beta+C_{S 2} \\
C_{Y M}=C_{Y M 1} \cdot \beta^{2}+C_{Y M 2} \cdot \beta+C_{Y M 3} \\
C_{P M}=C_{P M 1} \cdot \beta^{2}+C_{P M 2} \cdot \beta+C_{P M 3} \\
C_{R M}=C_{R M 1} \cdot \beta+C_{R M 2}
\end{array}\right.
$$

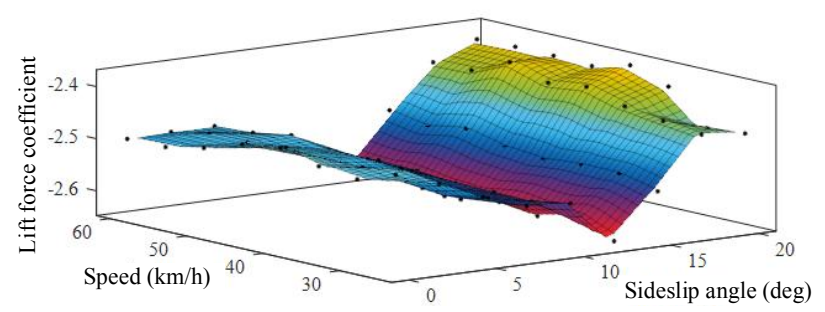

(a)

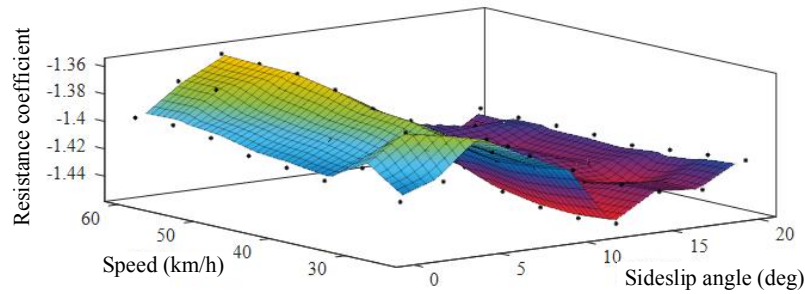

(b)

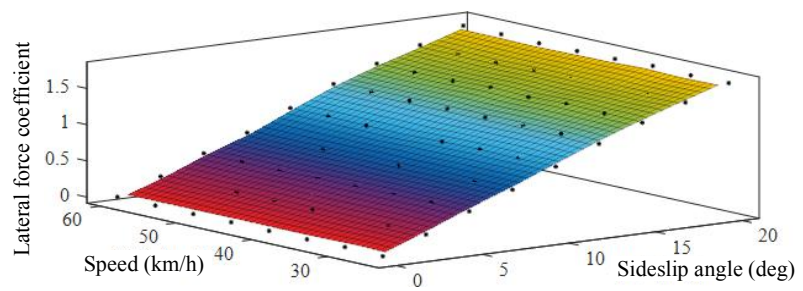

(c)

Figure 6. Relationship among aerodynamic force coefficient, speed and sideslip angle.

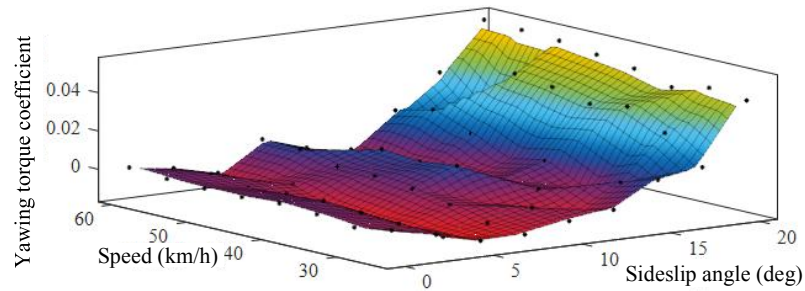

(a)

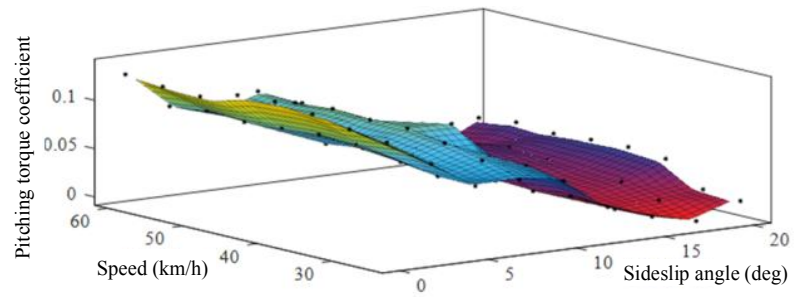

(b)

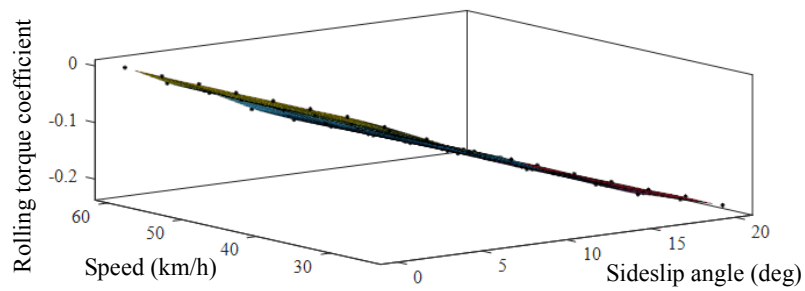

(c)

Figure 7. Relationship among aerodynamic torque coefficient, speed and sideslip angle.

Table 3. Windward velocity values of different sideslip angles.

\begin{tabular}{|c|c|c|c|c|c|}
\hline $\boldsymbol{C}_{\mathrm{L} 1}$ & $\boldsymbol{C}_{\mathrm{L} 2}$ & $\boldsymbol{C}_{\mathrm{L} 3}$ & $\boldsymbol{C}_{\mathrm{L} 4}$ & $\boldsymbol{C}_{\mathrm{D} 1}$ & $\boldsymbol{C}_{\mathrm{D} 2}$ \\
\hline 15.04 & -3.4 & -0.418 & -2.464 & 13.37 & -7.064 \\
\hline $\boldsymbol{C}_{\mathrm{D} 3}$ & $\boldsymbol{C}_{\mathrm{D} 4}$ & $\boldsymbol{C}_{\mathrm{S} 1}$ & $\boldsymbol{C}_{\mathrm{S} 2}$ & $\boldsymbol{C}_{\mathrm{YM} 1}$ & $\boldsymbol{C}_{\mathrm{YM} 2}$ \\
\hline 0.7923 & -1.404 & 5.103 & 0.02057 & 0.8002 & -0.1573 \\
\hline $\boldsymbol{C}_{\mathrm{YM} 3}$ & $\boldsymbol{C}_{\mathrm{PM} 1}$ & $\boldsymbol{C}_{\mathrm{PM} 2}$ & $\boldsymbol{C}_{\mathrm{PM} 3}$ & $\boldsymbol{C}_{\mathrm{RM} 1}$ & $\boldsymbol{C}_{\mathrm{RM} 2}$ \\
\hline 0.002 & 0.7141 & -0.5481 & 0.1252 & -0.6358 & -0.011 \\
\hline
\end{tabular}




\subsection{Aerodynamic forces calculation in bend}

Data of this section are from the simulation results in previous section. Considering the driving path under different speeds, solve the change regulation of six aerodynamic component forces under the corresponding driving path. The car speed and the windward speed are the same, it can be seen that windward speed decreases slower from Table 3 . It can be assumed that vehicle move at a constant speed in whole process. The vehicle route is selected in accordance with the windward speed and set the maximum allowable speed as windward speed. Road adhesion coefficient is selected 0.9. Corresponding curve radius $R$ can be given by:

$$
R=V_{a}^{2} / \mu g
$$

Corresponding driving time of side slip angle change from $0^{\circ}$ to $20^{\circ}$ can be calculated by:

$$
T=\frac{\pi R}{6 V_{a}}=\frac{\pi V_{a}}{6 \mu g}
$$

Sideslip angle $\beta$ can be expressed as:

$$
\beta=\frac{\pi}{6 T} \cdot t
$$

where $t$ is driving time at a certain angle in cornering. Substituting $\beta$ into Equation (2), coefficients variation with time can be obtained. So, aerodynamic forces and torques under $45 \mathrm{~km} / \mathrm{h}$ windward speed can be written as:

$$
\left\{\begin{array}{c}
F_{D}=499.869 t^{3}-374.298 t^{2}+59.497 t-149.423 \\
F_{L}=562.306 t^{3}-180.155 t^{2}-31.389 t-262.235 \\
F_{S}=383.207 t+2.189 \\
T_{R M}=-73.050 t-1.791 \\
T_{P M}=57.892 t^{2}-62.947 t+20.387 \\
T_{Y M}=64.872 t^{2}-18.073 t+0.126
\end{array}\right.
$$

Aerodynamic forces and torques under windward speed of $45 \mathrm{~km} / \mathrm{h}$ are shown in Figure 8 and Figure 9.

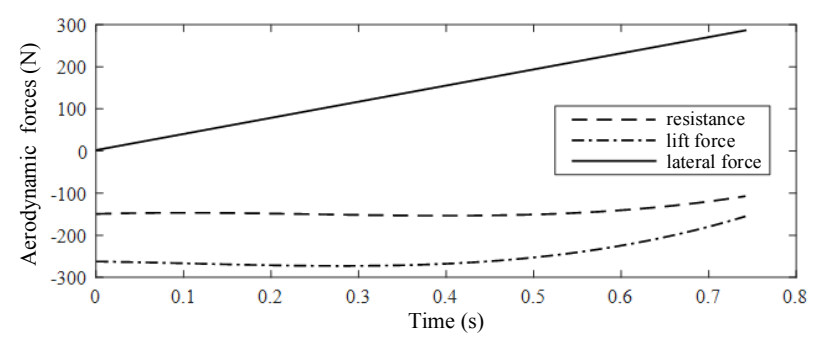

Figure 8. Aerodynamic forces under windward $45 \mathrm{~km} / \mathrm{h}$.

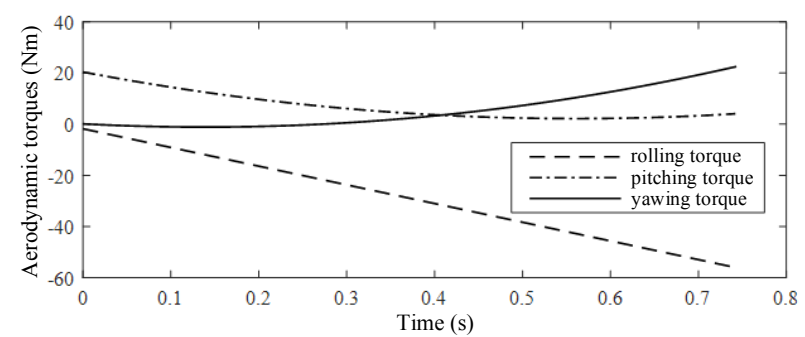

Figure 9. Aerodynamic torques under windward $45 \mathrm{~km} / \mathrm{h}$.

\section{Conclusion}

This paper presents an effective method to study the aerodynamic characteristics of a racing car based on wind tunnel test and computational fluid dynamics simulation. Aerodynamic model of a racing car is established, and six aerodynamic component forces are defined. Wind tunnel experiment is completed, and accuracy of computational fluid dynamics simulation is verified based on the comparison between experimental and simulation results. Flow field model of racing car is established and the coefficients of six aerodynamic forces under transient conditions are fitted, and the aerodynamic equations are obtained. Finally, the aerodynamic forces and torques of the racing car travel in bend under $45 \mathrm{~km} / \mathrm{h}$ windward are calculated and analysed.

\section{Reference}

1. J. A. Mohrfeld-Halterman, M. Uddin, High fidelity quasi steady-state aerodynamic model effects on race vehicle performance predictions using multi-body simulation. Vehicle System Dynamics. 54(7): 963981, (2016).

2. J. D. Kee, J. H. Rho, et al., High speed driving stability of passenger car under crosswind effects. International Journal of Automotive Technology. 15(5): 741-747, (2014).

3. Luke S Roberts1, Joao Correia, et al., Aerodynamic characteristics of a wing-and-flap configuration in ground effect and yaw. Journal of Automobile Engineering. 230(6): 841-854, (2015)

4. A. Buljac, I. Džijan, et al., Automobile aerodynamics influenced by airfoil-shaped rear wing. International Journal of Automotive Technology. 17(3): 377-385, (2016).

5. M. D. Soso, P. A. Wilson, Aerodynamics of a wing in ground effect in generic racing car wake flows. Proceedings of the Institution of Mechanical Engineers Part D-Journal of Automobile Engineering. 220(D1): 1-13, (2006).

6. A. Altinisik, O. Yemenici, H. Umur, Aerodynamic Analysis of a Passenger Car at Yaw Angle and TwoVehicle Platoon. Journal of Fluids EngineeringTransactions of the ASME. 137(12): FE-15-1219, (2015).

7. A. Altinisik, Aerodynamic coastdown analysis of a passenger car for various configurations. International Journal of Automotive Technology, 18(2): 245-254, (2007).

8. Ying-Chao Zhang, Jing Zhao, et al., Wind tunnel tests and aerodynamic numerical simulations of car opening windows. Nonlinear Dynamics, 58(1): 62-78, (2012).

9. A. L. Smith, D. J. Mee, et al., Design, modelling and analysis of a six component force balance for hypervelocity wind tunnel testing. Computers \& Structures, 79(11): 1077-1088, (2001). 